\title{
Novel eco-friendly synthesis of neodymium doped zinc silicate phosphor based waste glass ceramic: structural, thermal and luminescence properties
}

\begin{abstract}
A novel $\mathrm{Nd}^{3+}$ doped $\mathrm{Zn}_{2} \mathrm{SiO}_{4}$ (at $\mathrm{Nd} 2 \mathrm{wt} \%$ ) phosphor have been synthesized at different sintering temperature $\left(600-1000^{\circ} \mathrm{C}\right)$ by low cost solid state route. For the first time, the ecofriendly based glass ceramic phosphor were produced by utilizing waste soda lime silica glass (SLS) and $\mathrm{ZnO}$ as precursor. The obtained samples were investigated in terms of thermal properties by DSC technique and the results showed a possible crystallization peak around $620^{\circ} \mathrm{C}$. The crystalline phase formation by XRD revealed $\alpha$-willemite at lower temperature of $800{ }^{\circ} \mathrm{C}$. The analysis by FTIR exhibit the existence of $\mathrm{ZnO}_{4}$ and $\mathrm{SiO}_{4}$ structural bonding. The microstructure analysis by FESEM revealed the evolvement from irregular blocks to crystalline structure. EDX analysis confirmed the presence of main element contained in the samples. UV-Vis spectroscopy shows absorption peaks from the ground ${ }^{4} \mathrm{I}_{9 / 2}$ state to various excited energy level of $\mathrm{Nd}^{3+}$ ion in $4 \mathrm{f}^{3}$ configuration. Under diode laser excitation of $800 \mathrm{~nm}$ photoluminescence, the samples shows possible upconversion emissions in the blue, green, orange and red region. Possible mechanism of upconversion were also studied proposing the suitability of $\mathrm{Nd}^{3+}: \mathrm{Zn}_{2} \mathrm{SiO}_{4}$ based waste glass ceramic for solid state laser.
\end{abstract}

Keyword: Eco-friendly synthesis; Sintering temperature; Waste glass ceramic 